\title{
LE NOUVEAU-GENTILHOMME DE MME D'AULNOY: FACTORES TRANS-CULTURALES EN LA CALIBRACIÓN DE LA SALUD MENTAL DE DON QUIJOTE
}

\author{
Clark COLAHAN \\ Whitman College \\ colahaca@whitman.edu
}

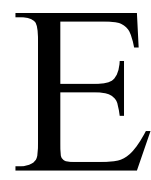
ntre los cuentos de hadas publicados por Mme d'Aulnoy en la última década del XVII y destinados a muchos años de éxito tanto en Inglaterra como en Francia, figura como historia de marco una pequeña novela de otro tipo, Le nouveau-gentilhomme, más realista y repleta de alusiones al Quijote. En 1970 observó Palmer que los especialistas de la influencia cervantina en Francia no le habían hecho caso, y hoy todavía, aunque con alguna que otra excepción, los vínculos de la historia con la obra maestra cervantina no se han estudiado detalladamente ${ }^{1}$. Tampoco se ha examinado el lugar del pequeño gentilhombre burgués dentro de la historia de las interpretaciones del protagonista cervantino nacidas y moldeadas en muchas culturas y épocas.

\section{Dos interpretaciones de marco, el Quijote existencialista del siglo XX y el pos-modernista del XXI}

A través de estas lecturas innovadoras, cada una hija de su propia época, ha sido fundamental la cuestión de la locura del ambicioso personaje, entendida por algunos como una forma de cordura extraordinaria. Frente a las varias formas de interpretar lo que Cervantes mismo entendía ser los móviles de la conducta, y la salud mental en general, de su ingenioso hidalgo, la crítica de las últimas décadas suele recurrir a la patología mental según la definía la medicina del XVI. Buen ejemplo es la reseña escrita por Otis Green al publicarse en 1958 tres conferencias del profesor norteamericano de literatura comparada Mark Van Doren con el título de Don Quixote's Profession. Esta, en el concepto de Van Doren, resulta ser la de actor, y uno que merece el respeto de los lectores por su diestro, y cuerdo, manejo del papel que ha emprendido. El distinguido estudioso y poeta así había desafiado al aspecto más positivista del historicismo dentro del cervantismo, sugiriendo en unas cien páginas los motivos del rechazo perenne por el público de una visión que suele dejar a muchos lectores insatisfechos y frustrados. Como comprobaremos en la recreación de la personalidad quijotesca por

\footnotetext{
${ }^{1}$ Véase Palmer (1970: 595). El presente estudio repasa las principales aportaciones posteriores al tema.
} 
D’Aulnoy, el reducir la génesis del protagonista a la enfermedad mental, entendida como principal fuerza motora dentro del esquema creativo de la novela, suele sentirse demasiado mecánico y deficiente, poco iluminadora de la generalmente aceptada importancia de la obra para la sociedad española de la época y la vida en general. Van Doren insinúa que, en su opinión, la fisiológica sería la solución más sencilla y elegante, como dicen los matemáticos, pero no la que más flor ha dado, la que mejor capta el impacto universal del Quijote.

Green, aunque reconociendo el derecho del poeta a entrar plenamente en la perspectiva del personaje, lo despacha de la siguiente manera crítica, de sabor netamente científico:

I believe it has been proved that Cervantes regarded his hero's intermittent derangements -when «se le encendía la cólera»- as having a physiological basis, and showed that these were mitigated by such cooling agents as sleep or a drink of cold water, and were brought to an end by the psychosomatic agent of melancolia (excessive black bile) caused by discouragement and sadness. It is in the lucid intervals that Don Quixote can sanely refrain from retesting his cardboard helmet and can view his adventures in the cave of Montesinos as akin to Sancho's 'visions' from the back of Clavileño. When the burning heat of cólera yields to the cold of melancolía, Don Quixote goes home to die (Green, 1960: 284).

Al leerse esto, si bien está pegado a la afirmación del narrador de que a Alonso Quijano se le secó el cerebro por leer demasiado, se puede objetar que tiene pinta de reduccionista, puesto que no se aclara la raíz profunda del sanativo desánimo y tristeza. ¿No ha aprendido Alonso Quijano, ni logrado, nada trascendente? A esto iba Avalle-Arce, quien en su rechazo por otros motivos de la lectura vandoriana protestó: «En mi opinión, el sentido del sueño de don Quijote cala demasiado hondo en el significado trágicamente heroico de la vida para asociarlo al deleznable arte de birlibirloque de cualquier tinglado de farsa» (Avalle-Arce, 1966: 268). Más entusiasta, aunque todavía cauteloso, se mostró Raimundo Lida, molesto por la insistencia de Van Doren en la imposibilidad de saber a ciencia cierta lo que realmente pensaba Cervantes. Parecido a Green en su búsqueda de una solución sólida y unificadora, resumió su apreciación así, «El ejercicio es saludable, si no confiamos demasiado en él» (Lida, 1958: 83).

\section{Van Doren y un Quijote de moral ascendente}

Los otros reseñadores a través de las seis décadas se han conformado al plan interpretativo de leer la novela lo mejor que se pueda en un marco más amplio, como reflejo de la experiencia humana que conocemos, sin pretensiones de una seguridad total. Hasta se han encariñado con el voluntarioso Quijote vandoriano, fiel al guión que ha elegido, a veces calculador. Esa interpretación se había destacado en el XVII -sin que la crítica le prestara mucha atención- en Le nouveau gentilhomme. Además, es reconocido no faltan elementos de la trama que apoyan dicha interpretación. Van Doren nos recuerda que Alonso Quijano es solo uno entre varios personajes de la novela que asumen papeles que no les corresponden dentro del orden habitual del mundo. Mantiene que el hidalgo, que según el poeta va rumbo a verdadero caballero, tiene sentido de humor, algo poco típico de los locos, y hasta inventa los sucesos de la Cueva de Montesinos para burlarse de Sancho. 
Van Doren pone hincapié en el acuerdo que le susurra don Quijote a Sancho en el episodio de Clavileño, la promesa de creer la mentira en ese momento inventada por el escudero a cambio de ser creído como inventor de las aventuras de la cueva. Esa lucidez la explica Green como un fenómeno momentáneo, un elemento de su fluctuante enfermedad mental. Pero, hay que preguntarse, ¿cómo saber en qué momento está cuerdo don Quijote y solo finge creer en los productos de su hiperactiva imaginación? Dónde está la raya entre un momento de profunda enajenación mental y el de hacer muy bien un papel asumido? No parece inconcebible la existencia de actores dispuestos a quedar realmente maltratados a cambio de hacer un papel de bastante relieve, como el de los molinos. Más bien parece cuestión de gustos críticos, y de la técnica cervantina fundamental de contar tanto el haz como el envés de las cosas, a la que tendremos que volver más abajo (Martínez Mata, 2008: 99-114).

Sin embargo, tanta ambigüedad no suele pervivir en los avatares de la novela, sean los realizados por otros novelistas o en la mente de los críticos. Tal vez nos aproximemos mejor a saber porqué un individuo dado cree que don Quijote sabe lo que hace tomando en cuenta el contexto cultural de la recreación literaria. El existencialismo del siglo pasado, y el romanticismo que le subyacía, se evocan en una reseña de Simon Leys del libro de Van Doren. Salida en 1998, se publicó dentro de la New York Review of Books y señala en la perspectiva del profesor una presencia del unamuniano Nuestro Señor Don Quijote, encarnación literaria de un destacado proyecto vital (Leys 1998).

Tal influencia no se contempla como ningún defecto. Al contrario, Leys afirma con Van Doren que el personaje cervantino, lejos de ser ningún loco, «After having considered other options, he finally decided that the career of a knight errant would be the most rewarding, intellectually and morally». ¿Cuál es, pregunta retóricamente, la diferencia entre portarse como un gran hombre y serlo? Para Leys la transcendencia del Quijote, su esperanza de una conducta ética, radica en un dicho de Iris Murdoch: «Man is a creature who makes pictures of himself, and then comes to resemble the picture». Para Pearson, afirmando con Van Doren que don Quijote llega a ser caballero, el hidalgo manchego alcanza «grandeza de espíritu»: «From acting the part of a knight to actually becoming a knight. Which is the reality, the professing or the being? [...]. This would seem to be about as near to reality as one can come in human endeavor» (Pearson, 1959: 16).

No obstante tanta grandeza, reconoce Van Doren que al campeón de la moral se le pueden atribuir algunos detallitos defectuosos, casos de conducta autoindulgente en lugar de altruista, pero el crítico logra mirarlos bajo una luz redentora, y a veces hasta hacerles caso omiso ${ }^{2}$. Durante la estancia de don Quijote y Sancho en casa de los duques, el capellán señala la vanidad, la inutilidad, de la vida a que se han dedicado ( $D Q$ II, cap. 31), pero Van Doren aborda esta cuestión fundamental recalcando la extraordinaria elección voluntaria del protagonista como admirable virtud (Van Doren, 1958: 88). Niega que don Quijote se haya creído caballero verdadero, y afirma que más bien se conceptúa como alguien en el camino de la auto mejoría, rumbo a la caballerosidad, sin deseos de engañar a nadie. En plan de contraste de personalidades, el profesor de literatura comparada menciona a Hamlet como personaje que sí llega a dudar de su propia identidad (Van Doren, 1958: 90-91). El hecho de no haberle

\footnotetext{
${ }^{2}$ Sobre estas tendencias criminales véase Fernández Nieto, Parra Luna y Colahan (2016: 141-151).
} 
socorrido a Sancho al ser este manteado en la venta, ni en la trifulca de los dos pueblos peritos en rebuznar, no se califica de cobardía sino de un vivo sentido de la comicidad, bromas entre buenos amigos. En términos más amplios, todo el proyecto vital del ambicioso hidalgo cincuentón -hacerse famoso en las armas buscando pleitos, casarse con una princesa por motivos interesados, y luego heredar un reino ( $D Q \mathrm{I}$, cap. 21$)$ - no se toma en cuenta.

Desde esta perspectiva típica del existencialismo del XX, es mejor concluir que don Quijote es autoconsciente y ejemplar. Por tanto Leys lamenta que el libro de Van Doren no se haya reeditado hace años, y en esto comparte el sentir de varios críticos. Tres generaciones antes Joseph Silverman calificó a las conferencias, recién publicadas, como una manifestación, bellamente redactada, de amor, humildad y profunda inteligencia que no dejaría de granjear nuevos lectores para la novela (Silverman, 1958: 326).

Asimismo las describió elogiosamente Angel del Río afirmando que «Este breve volumen contiene en sus noventa y nueve páginas, uno de los comentarios del Quijote más altamente sugestivos» (Del Río, 1959: 97). Del mismo estilo escribió Ynduráin: «Su interpretación tiene lugar por derecho propio a figurar entre las más distinguidas que el Quijote ha suscitado» (Ynduráin, 1958: 95). Sin embargo, la interpretación de Van Doren, por estar a caballo entre el más alto elogio de los valores del personaje cervantino y una prudente afirmación de que no lo podemos conocer a fondo, produce una inquietante ambigüedad.

El presente estudio le ha dedicado unas páginas debido a su llamativo contraste con el Quijote de D'Aulnoy, mucho más satírico y sin titubeos interpretativos, si bien los dos comparten en su retrato literario de la personalidad quijotesca un afán de llegar a la claridad de lo que llaman los físicos una Teoría Unificada de Campos.

\section{La commedia dell'arte y un Quijote en transformación continua}

Actualmente mucha crítica pos-modernista, conservando la idea vandoriana de un Quijote que ejerce la profesión de actor, se fija en la importancia de la improvisación dentro de la commedia dell'arte, un género dramático italiano seguramente conocido por Cervantes ${ }^{3_{3}}$. Aunque esta aproximación a la novela, a diferencia de la existencialista, no postula ningún carácter definitivo del protagonista como mensaje trasmitido por el autor, considera al hidalgo un ducho creador dramático de sí mismo en constante estado de transformación.

Citando a Nicoló Barbieri, actor de principios del XVII, sobre la inmensa cantidad de material típico que aprendían de memoria los actores de este tipo de comedia para ser utilizado en la representación de muchos tipos de personajes, afirma O’Neill:

Barbieri's words might equally well describe the modus operandi of Don Quixote, who has the ability to instantly transform himself into a host of different characters in order to adapt to the changing circumstances that he encounters on his travels. Indeed, it is his ability to do so that largely creates and

\footnotetext{
${ }^{3}$ Un buen resumen de los estudios recientes sobre la influencia de este género en Cervantes es el de O’Neill (2016). Véanse en especial las pp. 14-15.
} 
sustains the fiction [...]. According to Maravall, during the Baroque period life was not understood as factum, but as fieri, a process of becoming (O’Neill, 2016: 13).

Desde la perspectiva de esta interpretación, entonces, el factor siempre constante de la narrativa cervantina no se encuentra en la personalidad del protagonista, ni en ningún comentario del autor sobre la conducta que a lo largo de la historia lo caracteriza, sino en la técnica narrativa que presta energía a su llamativa personalidad.

\section{D'Aulnoy, culta aristócrata francesa conocedora de España}

En la Francia de los años declinantes del Rey Sol, Marie-Catherine Le Jumel de Barneville, mejor conocida como Mme D’ Aulnoy (1650?-1705), entendía a don Quijote de una manera que le parece al lector actual mucho más sencilla, aunque hacia el final de su novela se le metió un inesperado eco -al parecer al reflexionar sobre lo que tenía en común su protagonista con ella misma- de la matizada visión cervantina. Como condesa que era, veía como cosa de guasa que un hidalgo pobretón y viejo se dedicara a entrar en la aristocracia presentándose ante el mundo como un caballero. Por su parte, ella se dedicaba en la última década del XVII a lo que ella ayudó a poner de moda, los cuentos de hadas ${ }^{4}$. En el Siglo de las Luces que estaba por nacer, la crítica iba a ver con malos ojos la mágica, la fantasía y la libre invención. Pero el gran público, incluso las damas ilustradas, se sentía atraído tanto por la innovación estilística que desarrolló. Esta incluyó la cuidada y elegante utilización de una moraleja al final de los cuentos como en las fábulas de la época, como las tonalidades sentimentales de la materia tradicional que remodelaba ${ }^{5}$.

Como Cervantes al forjar su adaptación de las novelas caballerescas, ella se aprovechaba no sólo de la parodia, aunque mucho menos que aquel, sino también, y mucho más, de los atractivos emotivos menos sofisticados, los que se describen en la conversación sobre la literatura en la que intervienen el ventero y Maritornes ( $D Q$ I, cap. 32). La crítica reciente se ha dado cuenta de que las tramas de la escritora no son de pura evasión, construidas (como el Quijote) con elementos de realismo social que señalan las angustias de la vida cotidiana ${ }^{6}$. Por tanto, la fuerte presencia de la burla de las historias fantasiosas que marca Le nouveau gentilhomme, algo sorprendente en una escritora que vive de ese género literario, se va entremezclando, como veremos y como pasa también en el Quijote, con una cierta simpatía por los soñadores.

No debe sorprendernos que esta aristócrata francesa haya sentido una afinidad con el autor del Quijote. Además del éxito de la novela en Francia a lo largo del XVII, ella había pasado un tiempo en

\footnotetext{
${ }^{4}$ Sobre la gran popularidad que obtuvo d'Aulnoy en Inglaterra y Francia, y mantuvo después de su muerte, véase Robert (2004: 116).

${ }^{5}$ «Les contes de Madame d'Aulnoy sont en effet travaillés par des interférences, des influences, des références textuelles qui permettent de saisir le processus de fabrication d'un genre nouveau, engageant la problématique de l'imitation et de la création, de la tradition et de l'innovation qui traverse tout le siècle» (Robert, 2004: 80).

6 «These unusually dramatic and disquieting aspects of Mme d'Aulnoy's realism are important indicators of her views on her own day [e. g., cruelty, forced marriages and involuntary entrances into convents for women]. The Contes reflect, often incidentally, what must have been the equally harsh facts of ordinary daily life for many French people in the seventeenth century» (Adams, 1994: 18).
} 
la corte española debido al exilio allí de su madre, implicada desde 1669 en una conspiración dentro de la corte francesa. Consiguieron un éxito dos obras que escribió a base de esa experiencia, Voyage d'Espagne y Mémoires de la Cour d'Espagne, siendo esta publicada tres veces en Francia y una vez en Holanda (Robert, 2004: 71). Al confeccionar novelas sentimentales seguía la moda de utilizar nombres de personajes y escenarios españoles, entre ellos doña Juana, Don Fernand de Tolède, don Gabriel Ponce de Leon, Isidore, le compte d'Aguilar y la comtesse de Fuentès. Bardon ya ha notado el aprecio de la lengua española que ella manifestó en Voyage de Espagne: «la naïveté et la finesse des expressions, la force des proverbes et ce que les Espagnols appellent el pico, c'est-à-dire la pointe et la délicatesse de la langue» (cit. en Robert, 2004: 86, n. 47).

\section{Don Quijote como arribista francés}

La pretensión al ascenso social, en que no se fijó Van Doren, asume en Le nouveau gentilhomme una marcada prominencia y tono de necedad. El discurso de don Quijote a favor de los linajes que se van engrandeciendo y subiendo después de haber empezado en una punta muy baja ( $D Q \mathrm{I}$, cap. 21), muy grato a los lectores que hemos vivido después del establecimiento de la meritocracia, no produce más eco, al menos hasta el final de la novela satírica, que la burla y el rechazo ${ }^{7}$. Tampoco tiene el protagonista, la Dandinardière, dotes quijotescas de sabiduría ni generosidad que compensen su ambición mal fundada y rasgos de carácter desagradables y vulgares. Y esto a pesar de situarse d'Aulnoy al borde de la avanzada de un enfoque en el hombre nuevo que se destaca cada vez más con el paso del XVIII (Adams, 1994: 13).

Los cuentos de hadas de d'Aulnoy, a los que esta novela de ligero sabor picaresco sirve de marco contrastado, están poblados por individuos que hoy llamamos astros, celebridades. Se fundan en la fantasía de la belleza, el lujo de príncipes y princesas, y los deseos satisfechos, si en parte por la virtud, de forma más llamativa y emocionante por la mágica . Claro que en la corte del XVII todavía abundaban practicantes de las artes negras u ocultas. Entonces D'Aulnoy juega, como Cervantes, entre el brindar a los lectores la fascinación de las aventuras de encanto y dejar claros los desastrosos resultados de tratar de vivir los cuentos fantásticos. En este sentido se destaca el cuento de La Princesse Printanière, en que una joven consentida se escapa con su galán a una isla desierta donde pronto se acaba no sólo el amor sino hasta las necesidades básicas de la vida (Maistre Welch, 1993: 83-85).

$\mathrm{Si}$ tal desenlace al idilio del amor primaveral recuerda a cierta distancia metafórica los descalabros de don Quijote, los puntos de contacto entre Le nouveau gentilhomme y la novela cervantina son más marcados y diversos. La autora toca todos los resortes cómicos, no sólo de Molière y otros escritores franceses, sino también de su modelo español ${ }^{8}$. El nuevo gentilhomme, hijo de un

\footnotetext{
${ }^{7}$ «Le bourgeois ridicule y rassemble les défauts les pus risibles et les plus vils. Diamétralement opposé au "bien né“ qu'il tente en vain d'imiter, il ne parvient qu'à se discréditer par sa folie prétention à l'élévation sociale» (Robert, 2004: 90).

8 «Madame de d'Aulnoy ne se privant d'aucune palette tonales, elle ne craint pas de recourir à des modèles comiques éprouvés, qu'elle parodie ou pastiche allégrement [...]. La conteuse fait ainsi référence, à plusieurs reprises, au Don Quichotte» (Robert, 2004: 86).
} 
rico mercader de París, se inventa un nuevo nombre. Si resulta risible 'Quijote', la pieza de la armadura que protege el muslo y así parece aludir a la timidez sexual del hidalgo solterón que nunca se ha declarado a la campesina que le apetece, y la Mancha como alusión paródica a una zona que dista mucho de ser una renombrada tierra misteriosa, está en la misma línea 'Monsieur de La Dandinardière' porque, aparte de sugerir ciertos tipos ridículos del teatro y el folclore, consigue ser tonto principalmente porque el que se lo pone piensa impresionar a sus vecinos por su aristocrática extensión (Robert, 2004: 728, n.3). Realzando la pretensión al ascenso social, d'Aulnoy agrega en el acto que su protagonista contrahace, y luego lleva en los bolsillos, cartas que supuestamente le escriben los grandes de Francia.

La armadura de ambos es anticuada, ingeniada para impresionar sin servir en el combate. La mitad del yelmo de don Quijote es de cartón, lo cual, como se trata de un buen actor, no le parece obstáculo a su salida al mundo para buscar aventuras. La Dandinardière, más práctico y enfocado en la alta costura francesa, va por los adornos improvisados ${ }^{9}$. En cuanto a su caballo, naturalmente le corre parejo a Rocinante en su decrepitud, pero hasta Clavileño, completo con cuerpo de madera y poderes de vuelo mágicos, aparece metido en uno de los cuentos que enmarca Le nouveau gentilhomme ${ }^{10}$.

La dama de sus pensamientos y además la hermana de esta, por si fuera poca la sátira, intensifican la mofa de las clases que aspiran a entrar en la aristocracia, también cambiando sus propios nombres, los que eran Marie y Marthe, por Virginie y Mathilde, sumamente literarios. Don Quijote conoce al dedillo la literatura caballeresca, pero estas damiselas reduplican su obsesión en este sentido y son capaces, según su mamá, de recitar todo el Amadís (Robert, 2004: 747). Como se ve al instante, ellas siguen en la impráctica estela del hidalgo, negándose a comer para así mantener un tono de alta espiritualidad $^{11}$. Su madre, como Teresa Panza después de calcular las ventajas implícitas, quiere insistirle a su esposo que sus hijas se casen entre la alta nobleza, aunque ni Sanchica, ni Marie ni Marthe, nada tiene de dinero para la dote. D'Aulnoy se burla directamente de tal madre arribista, mientras Cervantes lo deja al lector pensante ${ }^{12}$. En cuanto a la forma de pensar del enamorado en su amada, es conocida la reveladora afirmación que le hace don Quijote a Sancho de que Dulcinea es, en realidad, la campesina Aldonza Lorenzo ( $D Q$ I, cap. 25). La Dandinardière también muestra su cordura, y su deseo de cambiar el mundo a fuerza de sus poderes imaginativos, al declarar que

${ }^{9}$ «Il avait orné son casque d'un vieux bouquet de plumes, et pour se rendre encore plus terrible, il coupa la queue d'un assez joli cheval qu'il avait et la laisse flotter comme un panache sur ses épaules, son épée était des plus antiques» (Robert, 2004: 741).

${ }^{10}$ En La chatte blanche al príncipe lo llevan de cazar la princesa Gata Blanca y las manos sin cuerpo que siempre lo atienden: «Lui présentèrent un cheval de bois qui courait à toute bride, et qui allait le pas à merveille; il fit quelque difficulté d'y monter, disant qu'il s'en fallait beaucoup qu'il ne fût chevalier errant comme don Quichotte» (Robert, 2004: 762).

11 «L'on avait bien qu'elles regardaient la nécessité de manger comme un défaut de la nature où elles voulaient remédier en y résistant opiniâtrement, et bien souvent elles en tombaient en faiblesse» (Robert, 2004: 844). Se trataba de una corriente que también aprovechó Molière en Les femmes savantes. Véase Robert (2004: 844, n. 4).

12 Madame de Saint-Thomas, «qui avait aussi ses visions», le dice a su marido: «Vous savez quels sont nos ancêtres. Serions-nous capables de mésallier notre sang, et d'en avilir la noblesse par un mariage inégal?... Ne dois-je point en cas pareil être consultée, et mon avis n'est-il pas aussi judicieux que le vôtre? Non, monsieur, mes filles n'épouseron qu'un marquis ou un comte» (Robert, 2004: 745). 
considera a Virginie tan digna de ser princesa como la más alta nacida. Aquí empieza a derretirse, al parecer bajo la influencia cervantina, el desprecio que siente d'Aulnoy por su protagonista ${ }^{13}$.

El padre de las hermanas francesas, un barón empobrecido, opina que son tan extravagantes en sus ideas que harán empeorar el estado mental del fingido caballero. Este, efectivamente, no se caracteriza como loco, sino como necio. Se acusa la diferencia de matiz en el retrato del protagonista en relación con su prudente cobardía, como veremos, pero también nítidamente en su esfuerzos por conquistar el corazón de Virginie. A diferencia del amor estilizado entre don Quijote y su imaginaria Dulcinea, la sensata táctica del nuevo gentilhombre es convencerle de que él, como ella, tiene la inteligencia necesaria para escribir cuentos de hadas, aunque tontamente lamente no haber visto estas ni saber dónde habitan ${ }^{14}$.

\section{Un Quijote que desciende de hidalgo a bourgeois}

Los hidalgos de finales del XVI solían reunirse en públicos ejercicios ecuestres/marciales para recordar su papel en la Reconquista e insistir en su nobleza. Sin embargo, un buen número de ellos también se lanzaban al comercio, en contra de su estatus legal de libres del pago de impuestos y a la vez obligados a no trabajar en ningún oficio. Don Quijote es blanco de sátira social dirigida por Cervantes contra aquellas ínfulas de grandeza, pero el pobre hidalgo mantiene cierta dignidad por su aspiración, al menos en sus resonantes declaraciones de altruistas propósitos, a fortalecer en el mundo los ideales de la nobleza. La Dandinardière no sube a ese nivel. Es materialista y desgraciadamente ha heredado de su padre mercader mucho dinero con que fingir mejores cualidades. Hasta aparece en la novela una prima suya que maneja el mismo embuste (Robert, 2004: 1003). La hipocresía con que intenta aparentar las virtudes oficiales de la sociedad, una imagen pública claramente más insinceramente sentida que la de Alonso Quijano, lo convierte en una figura bastante menos simpática. En su caso no hay ambigüedad cervantina, al menos hasta el final.

Ambos caballeros fingidos contratan a un campesino como ayudante, pero el francés, llamado Alain, no supera el aire de simple de que se despoja Sancho en poco tiempo. Aquel funciona más como valet encargado de las obligaciones pesadas. Sobre él cae en particular el fardo de la falsa valentía de su prudente amo. Hemos visto que eso le pasa de vez en cuando a Sancho, pero en un grado tan inferior y poco notado por los lectores que se comenta que las similitudes entre los protagonistas están limitadas principalmente por la falta de valor del francés: «C'est un homme riche, il est un peu don Quichotte, mais ces extravagances lui passeront plus aisément; car il n'est pas si brave qui lui» (Robert, 2004: 794). Se reitera tanto el tópico que funciona retóricamente como las belicosas derrotas sin fin de don Quijote. La Dandindardière llega al extremo de vestir a Alain en su armadura para evitar así un duelo que él mismo ha provocado con un vecino. El narrador no espera que el lector note este rasgo absurdo

\footnotetext{
${ }^{13}$ Concediendo la realidad del hecho de que en su región se escasean las princesas, La Dandinardière no titubea en declarar: «Mais celle que j'adore mérite de l'être et à mon égard c'est tout comme si elle l'était» (Robert, 2004: 793).

14 «Pourvu que je fasse un conte pur convaincre Virginie que je n'ai guère moins d'esprit qu'elle; tout ce qui me chagrine c'est que je n'ai jamais vu de fées, et que je ne sais pas même où demeurent» (Robert, 2004: 795).
} 
(claro, desde la perspectiva aristocrática); ya al iniciarse la transformación del burgués en fingido gentilhombre se habla de la táctica de las apariencias: «Il apprit même à faire des armes, voulant passer pour brave [...] se disant homme de grosse qualité, et pour le persuader il faisait des mensonges ridicules à tout le monde» (Robert, 2004: 727).

La tantas veces comentada sabiduría y elocuencia del hidalgo, fruta de continuas lecturas en su extensa biblioteca, le han transmitido un respeto que comparten casi todos los personajes. Pero en el mundo burgués de Francia que empieza a imponerse hasta en el ambiente de la corte, no solo se compra la valentía, sino también la erudición. La Dandinardière se compra una gran biblioteca de un estudioso recién fallecido. Pero si la de Alonso Quijano es quemada por el cura como fuente de ideas nuevas y peligrosas, la del arribista francés termina disuelta por las lluvias al yacer sin ser leída en un montón fuera del castillo donde descansa su nuevo dueño (Robert, 2004: 846). Y en cuanto a castillos, el burgués hace construir uno nuevo y lujoso que se conforma al estereotipo de las novelas caballerescas (Robert, 2004: 728). Don Quijote, quien alaba y pone en práctica la autosuficiente costumbre caballeresca de dormir al aire libre, sale del castillo de los duques harto de la hipocresía de los ricos que la sociedad denomina grandes de España. Lógicamente los duques pueden haber tenido cierto impacto en el dibujo que hace d'Aulnoy de la falsa caballería francesa. En tales casas se come hasta el hartazgo, y la Dandinardière, aunque por las apariencias diga que es abstemio en cosas de la mesa, pronto cede a las incitaciones de sus burlones amigos a fortalecer el cuerpo para los futuros combates (Robert, 2004: 736).

\section{Los móviles de los caballeros, y los escritores}

La agenda de don Quijote, al menos en la Primera Parte de la novela -obtener la fama por el combate, tomar una princesa como esposa, y heredar un trono- está discretamente velada, menos en contados momentos, por un proclamado intento de restaurar la Edad de Oro, mítica época de paz y justicia. La de La Dandinardière se le parece mucho, pero sin el velo. Se pone hincapié en la esposa y el caudal, y el lamento por la decadencia actual del mundo se reduce a pocas palabas pegadas al final: «Mais je prétends aussi qu'elle soit riche, et dans le temps des fées j'aurais bien trouvé le moyen d'avoir une reine [...]. À présent si l'on est né pauvre et que l'on veuille s'enrichir, il faut travailler comme des loups, bien souvent même sans réussir: O tempora, o mores!» (Robert, 2004: 792). Los móviles de los aristócratas que llegan a conocer al protagonista también son similares entre sí. Los ricos y ociosos duques, aunque obligados a pedir dinero a agricultores enriquecidos, montan y disfrutan crueles entretenimientos. Los nuevos amigos 'bien nacidos' del burgués le instan por motivos sádicos a entrar en duelo con un vecino, de quien tiene gran miedo. Más impactante aun en la trama es el deseo de ellos que se case con una de las hijas del barón, y solo porque él es acaudalado y enamoradizo.

¿Qué es lo que logran ambos protagonistas alterando su forma de vida? El cervantino abandona sus fantasiosos esfuerzos por transformarse y luego se va a otro mundo menos duro. La Dandinardière no tiene que pasar por la muerte y efectivamente consigue mujer, castillo, y un lugar dentro de la 
aristocracia, además de una guía a vivir para siempre en el mundo de la fantasía, puesto que Virginie le va a enseñar a dedicarse a escribir cuentos de hadas.

On lui donne une très grosse dot, une revenue qui vaut mieux que la plus belle terre de ce pays. - Vous voulez dire des maison à Paris, reprit Dandinardière, ou des rentes sur l'Hôtel de Ville? - Ce sont là de plaisantes bagatelles, dit le prieur, on lui donne le don de faire des contes, et vous ne savez pas où cela va (Robert, 2004: 961).

Siempre pragmático y dedicado al comercio, el novio insiste que su propia producción futura de cuentos entre como cláusula en el contrato matrimonial (Robert, 2004: 962). Como observa Mainil (2008: 31), con el toque de una varilla mágica los cuentos se hacen bienes contables. Hasta se le dice que los sabios están preparándose para escribir su biografía. Poderoso caballero es don Dinero. Es una determinación que se dice justificada por el hecho de que el nuevo gentilhombre -mediante una hazaña que revela «l'heureuse fécondité de sa mémoire»- se ha aprendido toda la comedia del Cid de Corneille (Robert, 2004: 1046). Resulta como si don Quijote le creyera a Sancho cuando le dice en el último capítulo que Dulcinea ha quedado desencantada. Es una parodia de otra que por fin le ha dado cara a la realidad. Es un Quijote que sí ha sabido sacar provecho de lo que hacía.

¿Qué resonancias deberían haber sonado dentro del alma de Cervantes, y la de d'Aulnoy, al llegar al fin de la historia? El valiente soldado y narrador de grandes verdades siempre veía, como ya mencionamos, el haz y el envés de las cosas. Dado que le brotó en el acto creativo el arco íntimo de alguien que empezó con mucho de salteador y terminó con bastante de santo, sentiría que captar la verdad es imprescindible, pero tiende a ser fatal al impulso vital. Lo único que se puede resolver es a vivir como los burgueses que salen a pasar el fin de semana en la Falsa Arcadia ( $D Q$ II, cap.58), conociendo y obedeciendo los mandatos del mundo empírico en lugar de dejarse atropellar por las fuerzas primitivas.

D’Aulnoy, que vivía de escribir cuentos mágicos, tenía la costumbre feminista de formar heroínas que crean sus propias heroínas y héroes (Mainil, 2008: 9). ¿En qué se diferencia ella de Virginie y La Dandindarière que se lanzan a una carrera de imaginar fantasías para la aristocracia? Sería una sensación agridulce. D’Aulnoy se dio cuenta de que el cuento de hada era un nuevo género, menor en los ojos de los sabios, y supo aprovecharse de esta oportunidad de experimentar en la forma y el mensaje ${ }^{15}$. Triunfa el soñador siempre pragmático en lo que pretende, y como su creadora escribió, «Il rêva en effet, et ce fut beaucoup plus à Virginie qu'aux fées» (Robert, 2004: 792).

\section{Conclusión}

En su conquista literaria mundial el Quijote ha habitualmente provocado tanto la duda como el entusiasmo. A menudo se reflexiona sobre la cuestión de la extraordinaria conducta del protagonista, y se pregunta si se explica y se reduce a su esencia recordando la afirmación del narrador de que se le

\footnotetext{
${ }^{15}$ «Les femmes de lettres auxquelles le petit genre du conte offre l'espace de liberté surveillée qui leur permet de briller, tout en les cantonnant dans la pratique d'un genre mineur «inoffensif [...]. Les Contes se construisent donc avec et contre une tradition littéraire qu'ils s'efforcent de renouveler sans tout à fait s'en détacher» (Robert, 2004: 79, 85).
} 
secó el cerebro y se volvió loco. Lo típico es ajustar los elementos preferidos de la novela para que formen un nuevo conjunto. En esa remodelación se siente seguridad de don Quijote sí sabe lo que busca y que sus actos van conscientemente hacia esa finalidad. Buen ejemplo es el Quijote existencialista del XX, elocuentemente retratado por Van Doren. Como magnífico actor, este hidalgo no desvaría sino representa un papel que ha elegido. Dispuesto a aguantar las derrotas materiales que encuentre en el camino, se va haciendo más sabio y más noble, hasta convertirse en un auténtico caballero del espíritu.

El burgués francés arribista, durante casi toda la trayectoria de su transformación en miembro bien establecido de la aristocracia, da la misma impresión de perseguir una meta claramente asumida, pero invertida y dedicada al materialismo combinado con la aceptación aristocrática. D'Aulnoy, perspicaz lectora del Quijote, da personalidad a un hijo de mercader que sigue los pasos más conocidos del modelo cervantino. Los sigue de cerca en su sátira social y sus bufonadas, pero constantemente exagerando la tendencia a la ganancia personal que sólo ligeramente, como la otra cara de la moneda, se vislumbra en don Quijote. Los aristócratas que entran en la trama son igual de interesados y frívolos que los cervantinos, aunque, por obligación a la clase a que pertenece la autora, bastante menos crueles.

Pero la perspectiva de todo autor difícilmente puede escaparse de su situación personal. Cervantes, iniciando la historia de un salteador que parecía ir poco lejos, terminó volcándose en dos tomos de meditaciones que nacieron de un hombre valiente, ilustrado, ambicioso, y hasta comprometido con la moral. Hoy se han olvidado, o disculpado, los antecedentes criminales de la 'niñez' de don Quijote, puesto que los rasgos de su autor terminaron imponiéndose enérgicamente en el balanceo entre el egoísmo del criminal y el altruismo del santo.

D’Aulnoy compuso la mayor parte armada de desprecio por la burguesía, la que representaba una amenaza muy real -como llegó a verificar la historia- a los intereses creados de muchos de sus lectores. Sin embargo, ella también no pudo dejar de ver el envés de la sátira que era su punto de partida. El dedicarse a escribir cuentos de fantasías era tanto su métier como su evasión a un mundo mejor, como al fin de la jornada lo era de Monsieur de la Dandindarnière, y no pudo, a pesar del pragmático materialismo de este, evitar identificarse con él.

\section{Obras citadas}

ADAMS, D. J. (1994): «The 'Contes de fées' of Madame D'Aulnoy: Reputation and Re-Evaluation», Bulletin of the John Rylands University Library of Manchester, 76, pp. 5-22.

Avalle-Arce, Juan Bautista (1966): Reseña de Cuestión de límites. Cuatro ejemplos de estéticas fronterizas (Cervantes, Velázquez, Goya, el cine) por Guillermo Díaz-Plaja, Hispanic Review, 34, pp. 266-268.

FERnández Nieto, Manuel - PARRA LunA, Francisco - Colahan, Clark (2016): «El lugar de la Mancha y la génesis del Quijote: ¿Choque, o confluencia de letras y ciencias sociales?», Cervantes: Bulletin of the Cervantes Society of America, 36, pp. 123-155. 
GreEn, Otis H. (1960): Reseña de Don Quixote's Profession por Mark Van Doren, Hispanic Review, 28, pp. 283-284.

LEYS, Simon (1998): «The imitation of Our Lord Don Quixote», The New York Review of Books, June 11, en http://www.nybooks.com/articles/1998/06/11/the-imitation-of-our-lord-don-quixote/ (última consulta, 29-12-2017).

LIDA, Raimundo (1958): Reseña de Don Quixote's profession por Mark Van Doren, Nueva Revista de Filología Hispánica, 12, pp. 83-85.

MAINIL, Jean (2008): «Le sourire des fées: Aux origines du merveilleux comique», Féeries: études sur le conte merveilleux, XVIIe-XIXe siècle, 5/2008, revues.org, «Le rire des conteurs»; en http://hdl.handle.net/1854/LU-2974222 (última consulta, 29-12-2017).

Maistre Welch, Marcelle (1993): «La Satire du rococo dans les contes de fées de Madame d'Aulnoy», Revue Romane, 28, pp. 75-85.

MARTínez MAtA, Emilio (2008): Cervantes comenta el Quijote. Madrid, Cátedra.

O'NEILL, John (2016): «Improvisation in La entretenida: Tracing the Influence of Plautus and the Commedia dellárte on Cervantes», Cerantes, Bulltein of the Cervantes Society of America, 36, pp. 11-37.

PALMER, Melvin D. (1970): «Madame d'Aulnoy and Cervantes», Romance Notes, 11, pp. 595-598.

RoBert, Raymonde, ed. et trad. (2004): MADAME D'Aulnoy, Contes des fées suivis des Contes nouveaux ou Les Fées à la Mode. Édition critique par Nadine Jasmin. Paris, Honoré Champion.

PEARSON, Justus R. (1959): «Greatness of Mind», reseña de Don Quixote's Profession por Mark Van Doren, South Atlantic Bulletin, 25, p. 16.

Del Río, Angel (1959): Reseña de Don Quixote's Profession por Mark Van Doren, Revista Hispánica Moderna, 25, pp. 97-99.

Silverman, Joseph H. (1958): Reseña de Don Quixote's Profession por Mark Van Doren, Books Abroad, 32, p. 326.

VAn Doren, Mark (1958): «Don Quixote's Profession», en The Happy Critic and Other Essays. New York, Hill and Wang American Century Series, 1961, pp. 88-143.

YNDURÁIn, Francisco de (1958): Reseña de Don Quixote's Profession por Mark Van Doren, Anales Cervantinos 7, pp. 293-295. 